\title{
Optimal Sizing and Control of Solar PV-PEMFC Hybrid Power Systems
}

\author{
Vipin Das \\ Electronics and Communication Engineering Department, \\ M. N. National Institute of Technology Allahabad, Prayagraj, India. \\ Corresponding author: rel1512@mnnit.ac.in \\ Pitchai Karuppanan \\ Electronics and Communication Engineering Department, \\ M. N. National Institute of Technology Allahabad, Prayagraj, India. \\ E-mail: pkaru@mnnit.ac.in \\ Asheesh Kumar Singh \\ Electrical Engineering Department, \\ M. N. National Institute of Technology Allahabad, Prayagraj, India. \\ E-mail: asheesh@mnnit.ac.in

\section{Padmanabh Thakur} \\ Electrical Engineering Department, \\ Graphic Era (Deemed to be University), Dehradun, India. \\ E-mail: tonu_arth@rediffmail.com
}

(Received on April 13, 2021; Accepted on June 16, 2021)

\begin{abstract}
This paper explores several possible hybridized techniques to supply electrical energy at remote locations where the utility grid extension is found uneconomical. In this work, diesel-generator (DG) is combined with the various renewable energy resources (RES) and multiple storage facilities, such as (i) proton exchange membrane fuel cell (PEMFC) and hydrogen energy storage (HES), (ii) PEMFC, HES, and Solar PV, and (iii) HES, Solar PV, PEMFC, HES, and battery storage system (BSS), respectively, to achieve the best hybrid solution to supply electrical power in remotely located area efficiently. The Homer Pro software developed by the national renewable energy laboratory is used in this paper for conducting the proposed analysis. The problem is formulated as a multi-objective optimization problem to minimize the cost and greenhouse gas emissions. Three performance indices or objective functions, namely net present cost (NPC), levelized cost of energy (LCOE) and unmet load, have been evaluated for these three hybridizations to determine the best alternative to overcome the energy crunch, which is existing especially in remotely located area. The comparative analysis of the estimated performance parameters has revealed that the hybridization of DG with Solar PV, PEMFC, HES, \& BSS provides smaller values of NPC (in US \$), LCOE (in US \$/kWh), and unmet load. Furthermore, hybridization of DG with Solar PV, PEMFC, HES, \& BSS results in the lowest pollutant emission with zero unmet loads and energy wastage. Therefore, in this study, hybridization of DG, Solar PV, PEMFC, HES, \& BSS is recommended as the best alternative to supply electrical power efficiently and economically to remote areas. In this stand-alone work mode of operation of DG is considered as a reference system and named 'Combination 1'. The LCOE and NPC of the best suitable HPS are obtained as 0.50193 US \$/kWh and 35200000 US \$, respectively. As a result, the system's emission is reduced by $94 \%$ compared with the base case (combination 1).
\end{abstract}

Keywords- Homer pro, Levelized cost of energy, Net present cost, Solar PV, PEMFC.

\section{Introduction}

The energy-efficient economy is considered one of the most important and major factors to 
determine the country's growth. The use of renewable energy sources (RESs) for power production is often suggested as the best alternative for the development of energy-efficient economies and overcome the energy crunch existing due to the huge demand for electrical energy. Unfortunately, its competitiveness concerning traditional energy sources is low due to its poor conversion efficiency, high installation cost, and performance dependency on environmental conditions. Therefore, it is not recommended to utilize the stand-alone mode of operations. Instead, it is often suggested to hybridize RESs with reliable alternative energy resources to get optimum performance (Mazzeo et al., 2021) to address the drawbacks mentioned above. Nowadays, PEMFC is strongly suggested as the best alternative to RESs because of its several attributes: high efficiency, low carbon emission, and noiseless operation. However, the PEMFC possesses several disadvantages, such as slower dynamics (Salameh et al., 2021) and the requirement of pure Hydrogen as fuel (Lü et al., 2018). Therefore, hybridization of PEMFC with the solar photovoltaic (PV) and battery storage system (BSS) has been investigated in this work to overcomes its slower dynamics along with other alternative options. Basically, this work aims to provide the best alternative solution for designing a hybrid power system (HPS) to supply electric power at remote locations and areas of rugged terrains, where the extension of the utility grid is economically expensive.

This study presents energy management in HPS and the optimization of the HPS component using the HOMER Pro software. Here, the multi-objective type optimization problem is considered to reduce the total system cost and emission. Furthermore, hydrogen fuel production for PEMFC using solar PV makes it a 100\% RES-based system. Four types of combinations have been tested in this work to obtain the most optimal solution for HPS. The combinations are as follows:

(i) Combination 1: Diesel-generator (DG) only

(ii) Combination 2: DG-PEMFC-HES

(iii) Combination 3: DG-Solar PV-PEMFC-HESs

(iv) Combination 4: DG-Solar PV-PEMFC-HES-BSS

Here 'Combination 1' stand-alone mode of operation of DG. Further, the benefits obtained by adding the BSS to the system are highlighted by comparing these combinations. The major contributions of the paper can be highlighted as:

(i) A novel HPS using multiple energy storage systems (MESS) is developed.

(ii) The multi-objective problem is proposed and optimized.

(iii) The system performance is evaluated with and without MESS.

(iv) The developed system is sustainable with lesser cost and emission.

(v) Hybridization of RESs reduces the energy output from DG. Hence, the proposed work is also found suitable to overcome the global warming crisis and depletion of conventional fuels.

The remainder of the paper is structured in the following manner. The detailed literature survey is conducted in section 2. Then, in Section 3, the methodology is presented, followed by the system components' modeling in Section 4. The optimization problem formulation is covered in Section 5, and the simulation results are analyzed in Section 6, respectively. Finally, the conclusions are given in Section 7.

\section{Literature Survey}

Several attempts were already made to design efficient and optimal RES-based HPS (Kannayeram et al., 2020; Sultan et al., 2021; Talaat et al., 2021). In addition, the possibilities to reduce power 
fluctuations through the HPS have also been explored (Lande-Sudall et al., 2018). However, proper estimation of the optimal size of HPS and energy management between the resources has been considered the main challenging task in the design of HPS. Also, accurate estimation of the parameters, such as maintenance cost, operating cost, fuel cost, emission of pollutants, play a vital role in deciding the best combination of renewable energy resources for optimal and efficient design of HPS. Therefore, several research works were carried out to determine the optimal size of HPS through various artificial intelligence techniques, such as genetic algorithm (GA), particle swarm optimization algorithm (PSO), ant colony algorithms (Esfahani \& Yoo, 2016; Wang et al., 2021; Wen, 2020; Yuan \& Yang, 2019). However, accurate determination of the optimal size of HPS is not found suitable with AI-based techniques due to its several limitations. For instance, large numbers of parameters cannot be considered in AI techniques to design an accurate model for the HPS because of the slow speed of convergence. Hence, AI techniques are not suggested in determining the plants' actual optimum size (Jadli et al., 2018).

Further, several research works were also carried out to make sustainable and self-reliant HPS through a proper energy management system (EMS) between the RESs (Jannati et al., 2020; Kaluthanthrige \& Rajapakse, 2021; Restrepo et al., 2021). The system described in Zhang et al. (2021) uses solar PV \& wind power as energy sources and battery storage systems (BSS) as energy storage systems (ESS). However, in most of the literature, the HPS under consideration uses only a single energy storage system (Benlahbib et al., 2020; Dali et al., 2010; Arabul et al., 2017). In the proposed work, multiple energy storage systems (MESS), namely, BSS and hydrogen energy storage (HES), have also been incorporated to find an alternative to HPS. In this work, the Hybrid Optimization Model for Electric Renewables (HOMER Pro) software developed by the national renewable energy laboratory (NREL) is used for the designing of various power plant configurations, followed by the identification of the most optimized one, to various decisionmaking parameters, such as operating cost, net present cost (NPC), levelized cost of energy (LCOE) gases emission and economic comparison. In Akram et al. (2020), the HOMER Pro application for optimizing the RES-based HPS is presented. HOMER Pro is used to reduce the LCOE and NPC (Murugaperumal \& Raj, 2019). An off-grid HPS for remote locations has been developed using HOMER Pro (Rajbongshi et al., 2017). Different RES-based HPS for remote locations in Southern Cameroons are analyzed (Muh \& Tabet, 2019). The feasibility of rural electrification by conducting the techno-economic analysis using HOMER Pro is conducted in the literature (Krishan \& Suhag, 2019). Various HPS designs and optimization using HOMER Pro can be seen in the literature (Aziz et al., 2019; Dalton et al., 2009; Suman et al., 2021). The application and economic feasibility of the ESS in a microgrid are explained in Dhundhara et al. (2018). The use of pumped hydro storage system in microgrid using Homer Pro is discussed in Shabani et al. (2020). An improved artificial ecosystem-based optimization technique is used to conduct economic analysis considering LCOE and NPC are presented in Sultan et al. (2021). A cost and reliability analysis of a lecture building with a low load factor is conducted (Khalil et al., 2020) using Homer Pro. The design and modeling of HPS using Homer Pro can be seen from works of literature (Kumar et al., 2016). A technoeconomic case study of HPS in Bangladesh can be seen from the literature (Das et al., 2017). Another case study and practical implementation of HPS are discussed (Ahmad et al., 2018). The HPS design and implementation at the east coast zone of India is discussed in Parida et al. (2018). A computational simulation and design of HPS are presented in Oulis Rousis et al. (2018). Based on the literature survey conducted, the objective of the paper is formulated as:

(i) Design of suitable HPS with zero energy wastage and near-zero-emission. For powering the remotely located area. 
(ii) Explore the feasibility of MESS in HPS.

\section{Methodology}

As shown in Figure 1, the flow chart depicts the methodology adopted in this research work. First, the methodology consists of selecting the site, Solar PV availability, and energy demand estimation as a prerequisite. The next stage includes system modeling, and in the third stage, the optimization of the designed system has been conducted.
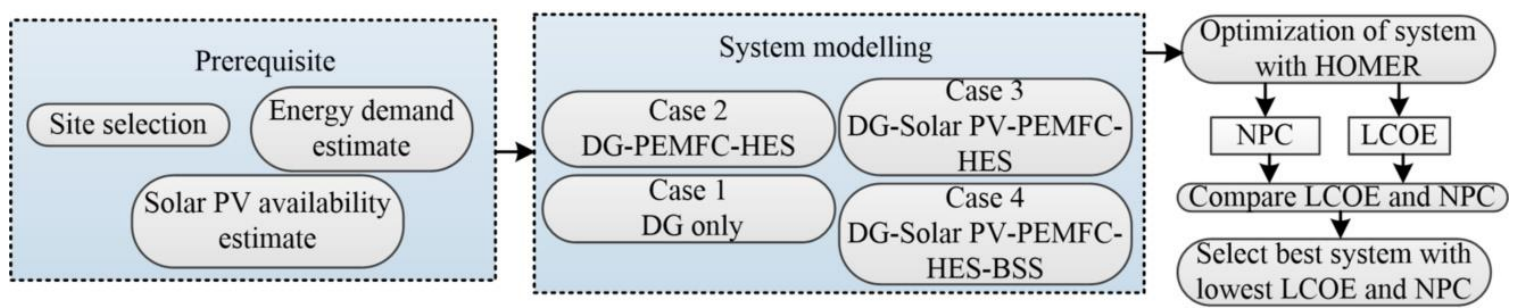

Figure 1. Flow chart for the proposed work.

\subsection{Site Selection}

A technical education institution, located in Uttar Pradesh, Prayagraj $\left(25^{\circ} 26.1^{\prime} \mathrm{N}, 81^{\circ} 50.8^{\prime} \mathrm{E}\right)$, is considered here as the candidate site for this study. The major loads include large motors installed at the laboratories, other machinery at various laboratories, lighting loads, air conditioning loads, and computer loads. The site under consideration is assumed to be powered by diesel-generator (DG) sets. In the proposal, the DG-based generation is replaced by the solar PV and PEMFC-based HPS to reduce the energy cost and emission.

\subsection{Solar PV Availability}

The generation of electricity through Solar PV depends on solar irradiance. The solar irradiation data of the location is taken from the HOMER Pro software database using the longitude and latitude $\left(25^{\circ} 26.1^{\prime} \mathrm{N}, 81^{\circ} 50.8^{\prime} \mathrm{E}\right)$ of the study location. The average yearly solar irradiation of the location is $4.93 \mathrm{~kW} / \mathrm{m}^{2}$. The plot of the global solar irradiation daily profile of the location is shown in Figure 2.

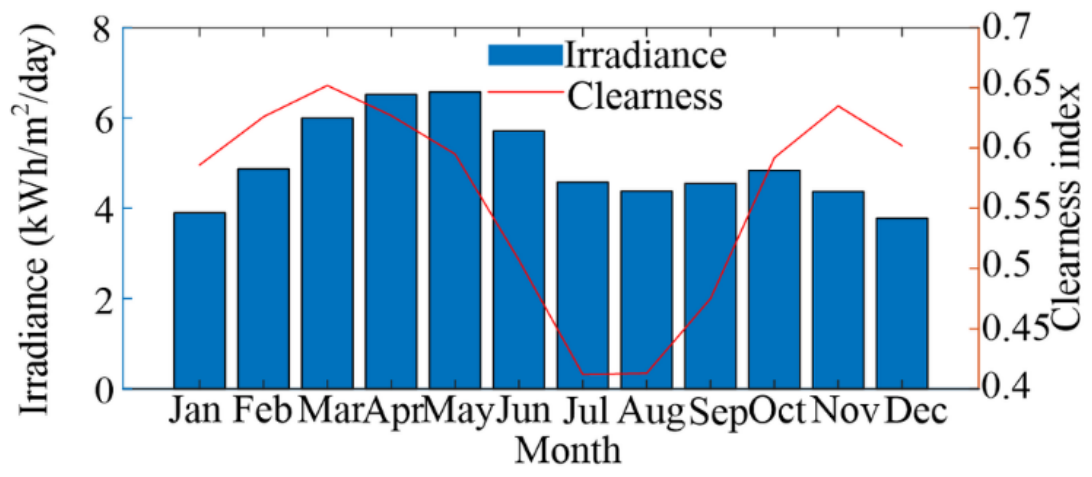

Figure 2. Monthly solar irradiation. 


\subsection{Energy Demand Estimation}

The total energy demand of the study site is estimated based on peak and average load. These values are estimated as $18874 \mathrm{kWh} /$ day (total energy demand for the day), $1317.9 \mathrm{~kW}$ (peak demand) and $619.75 \mathrm{~kW}$ (average demand), respectively. A load factor of 0.47 is considered in this work. Since the site under consideration is a technical educational institution, the peak time is 10 AM to 5 PM. Figure 3 presents the monthly average load profile.

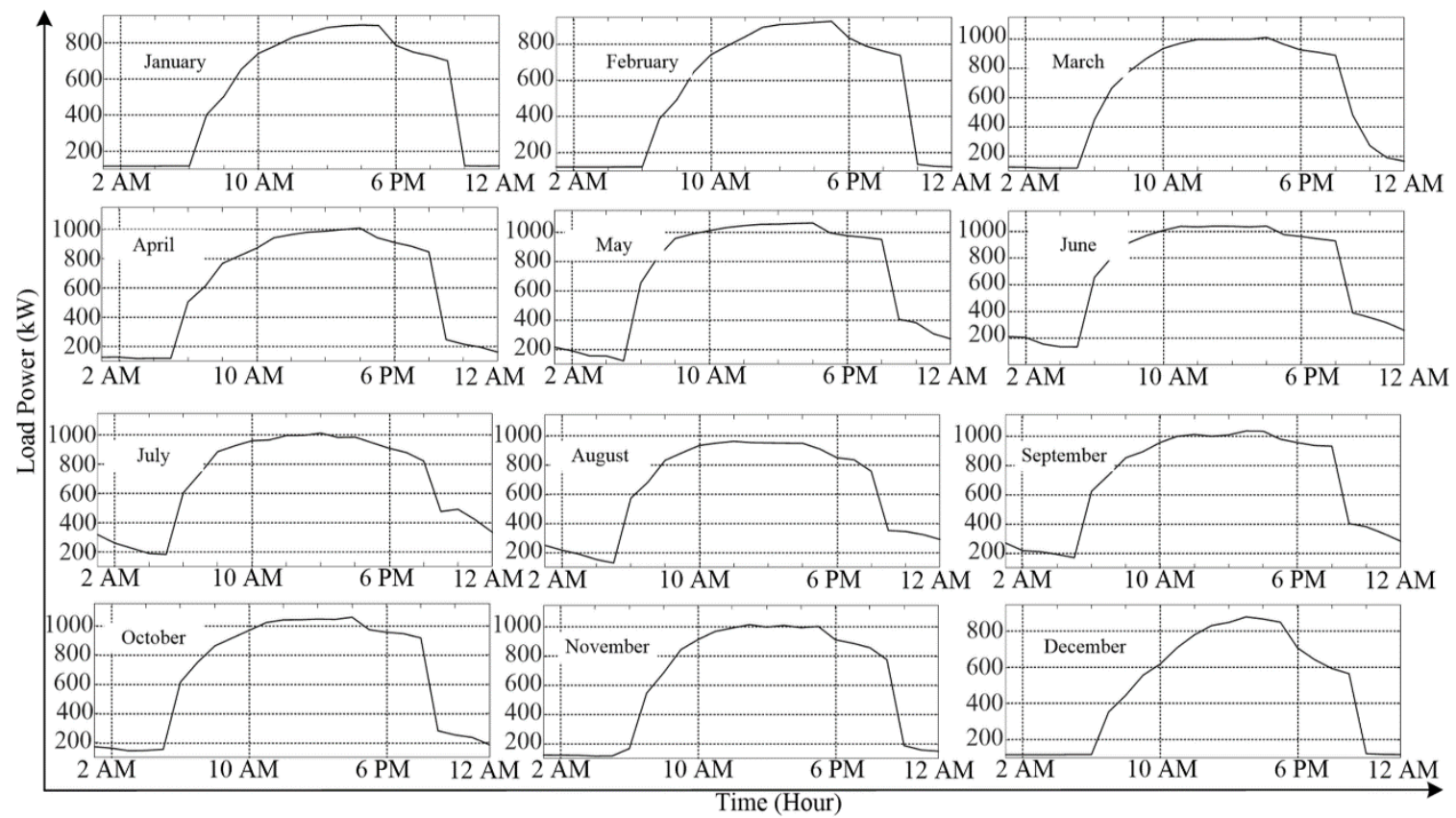

Figure 3. Monthly average load profile.

\section{Component Modelling}

The modeling of the HPS components is significant for size optimization. Therefore, the complete components of the HPS are modeled mathematically in this section.

\subsection{Solar PV}

The single diode model of the solar PV, shown in Figure 4, is used in this modeling. Equation (1) presents the solar PV module voltage (Suresh et al., 2020):

$V_{P V}=V_{m}\left[1+0.0539 \log \left(G(t) / G_{s t d}\right)\right]+\alpha(T(t))+0.02 G(t)$

where $V_{m}$ is the voltage at maximum power point operation, $G(t)$ is the variable solar irradiance, $G_{s t d}$ is the standard irradiance, $\alpha$ is the panel's temperature coefficient, and $T(t)$ is the variable temperature. Equation (2) gives the output current generated by the solar PV module:

$I_{P V}(t)=I_{p}(t)-I_{S}(t)\left[\exp \left(q V_{P V} / N_{S} K T(t) A\right)-1\right]$

where $I_{p}$ is the photocurrent, $I_{S}$ is the saturation current, $q$ is the charge of the electron, $N_{S}$ is the number of solar cells connected in series, $K$ is the Boltzmann's constant, and $A$ is the ideal diode factor. The total energy produced by the solar PV module is given by: 
$E_{P V}(t)=\left(N_{P V} \times V_{P V} \times I_{P V}(t) \times \Delta t\right)$

where $N_{P V}$ is the number of solar PV modules, and $\Delta t$ is the time step.

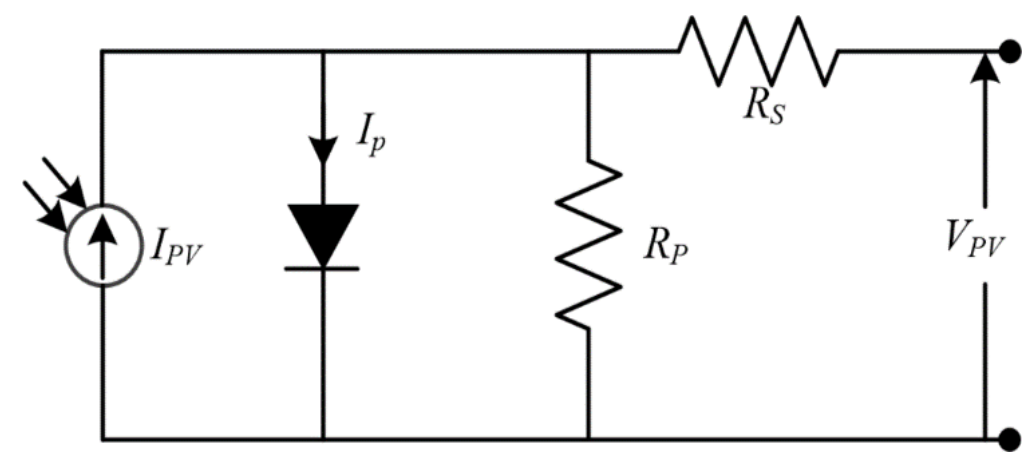

Figure 4. Solar PV equivalent circuit.

\subsection{PEM Fuel Cell}

The fuel cell (FC), one of the promising alternative RES, is electrochemical systems capable of converting the chemical energy of a hydrogen-containing fuel into electrical energy (Suresh et al., 2020). The FC behaves as a current source with variable output voltage, depending on the external load current. Its overall performance depends on several multi-dimensional input parameters, e.g., operational electrical current, temperature, and gas transportation characteristics (Suresh et al., 2020). The FC modeling is challenging as the physics and electro-chemistry governing the phenomena internal to the cell responsible for converting hydrogen input to electrical energy are not yet fully understood. The proton exchange membrane (PEM) FC is the most matured and widely used FC for power generation applications. The projected HPS consists of a PEMFC equipped with an electrolyzer chamber and a hydrogen tank. The electrolyzer chamber converts water to Hydrogen and stores it in hydrogen tanks. This stored Hydrogen is used as fuel by the PEMFC. The power output from the PEMFC can be given by the equation (Suresh et al., 2020);

$P_{F C}=P_{t} \times \eta_{F C}$

where $P_{t}$ is the input power to the PEMFC chamber, and $\eta_{F C}$ is the efficiency of the PEMFC.

\subsection{Electrolyzer Chamber/ Hydrogen Tank}

The electrolyzer chamber, working on the electrolysis principle, electrolyzes water with solar PV power. The equation (5) gives the power transferred from the electrolyzer to produce Hydrogen as: $P_{\text {ele }}=P_{\text {ren }} \times \eta_{\text {ele }}$

where $P_{r e n}$ is the renewable power input to the electrolyzer chamber (Solar PV power in this case), and $\eta_{e l e}$ is the efficiency of the electrolyzer chamber. Equation (6) expresses the energy output from the hydrogen storage tank (Suresh et al., 2020).

$$
E_{H S S}(t)=E_{H S S}(t-1)+\left[P_{\text {ele }}(t)-\left(P_{t}(t) / \eta_{s}\right)\right] \times \Delta t
$$

where $\eta_{s}$ is the efficiency of the hydrogen storage tank. 


\subsection{Battery Storage System (BSS)}

The BSS is used in this work to support the RES. The energy production of the BSS depends on the minimum and maximum values of state of charge (SoC). Equation (7) states the power available from the BSS (Suresh et al., 2020):

$E_{B S S}(t)=E_{B S S}(t-1)+E_{\text {surplus }}(t) \times \eta_{c c} \times \eta_{c h}$

where $E_{\text {surplus }}$ is the surplus energy available from other sources, $\eta_{c c}$ is the charging controller efficiency, and the $\eta_{c h}$ is the charging efficiency of BSS. The inequality relation (8) gives the constraints limiting the charging and discharging the BSS.

$S o C_{\min } \leq S o C(t) \leq S o C_{\max }$

The minimum value of SoC is obtained by the expression in terms of the depth of discharge (DOD):

$S o C_{\min }=1-D O D$

\subsection{Power Electronics Converter}

Here, a bi-directional DC/AC converter controls the AC and DC bus power flow. The converter's size depends on the minimum or maximum energy levels (Suresh et al., 2020). The bi-directional converter's main function is maintaining the power flow balance between the power generating sources and the ESS. The energy management system (EMS) controls this converter's operation based on the energy availability in the ESS.

\subsection{Energy Management System}

The EMS for the HPS depends on the charge available in BSS. Therefore, the EMS used in (Das et al., 2020) is adopted here. The algorithm always checks the BSS status; if its SoC is higher than the maximum limit (i.e., 90\%), then the solar PV's excess power diverts to the electrolyzer chamber. Similarly, the BSS is not discharged further for the SoC's minimum limit (i.e., 10\%). During this condition, the BSS starts charging if excess power is available from the solar PV. Further, if the SoC of the BSS is at a higher limit and the solar PV is unavailable, the BSS supports the load. Similarly, if the SoC of the BSS is at a minimum level and solar PV power is insufficient to meet the load, then PEMFC supports the load during this condition.

\section{Problem Formulation}

Here, the optimization problem is formulated to minimize the NPC, LCOE and pollutant emission. Various constraints, such as the SoC of BSS, the maximum and minimum limit of the hydrogen storage tank, upper and lower bounds of solar PV generation, PEMFC and BSS, have been considered to optimize the HPS size. In addition, power reliability is considered a constraint to develop the optimization problem, also.

\subsection{Objective Function}

The NPC and emission are considered as the objective function for this work. The NPC of the HPS can be given in mathematical form as (Suresh et al., 2020):

$N P C=\frac{C_{a t}}{\text { Capital recov ery factor }}$

where, $\mathrm{C}_{\mathrm{at}}$ is the total cost of annual energy. 
The emission, $\psi$ can be given by:

$\psi=\operatorname{Min}\left(\psi_{\mathrm{CO}_{2}}+\psi_{\mathrm{CO}}+\psi_{U H C}+\psi_{P M}+\psi_{\mathrm{SO}_{2}}+\psi_{\mathrm{NO}_{x}}\right)$

where UHC stands for unburned hydrocarbons and PM stands for particulate matters. The capital recovery factor $(\mathrm{CRF})$ is a function of annual interest rate $(i)$ and project lifetime $\left(N_{p r o j}\right)$. The CRF can be expressed mathematically as:

$C R F=\frac{i(1+i)^{N_{p r o j}}}{(1+i)^{N_{\text {proj }}}-1}$

Further, the total annual cost of energy $\left(C_{a t}\right)$ consists of the capital cost $\left(\zeta_{C}\right)$, operation and maintenance cost $\left(\zeta_{O \& M}\right)$, replacement $\operatorname{cost}\left(\zeta_{R}\right)$. The mathematical expression for the optimization problem can be given as:

$F=\min \left(C_{a t}\right)$

$C_{a t}=\xi_{a, C}+\xi_{a, O \& M}+\xi_{a, R}$

where, $\zeta_{a, C}$ is the annualized capital cost, $\zeta_{a, O \& M}$ is the annualized operation and maintenance cost and $\zeta_{a, R}$ is the annualized replacement cost. The capital cost $\left(\zeta_{C}\right)$, can be expressed as:

$\xi_{a, C}=\xi_{C} \times C R F$

The annualized operation and maintenance cost can be given as:

$\xi_{a, O \& M}=\xi_{O \& M} \times t_{O \& M}$

where, $t_{O \& M}$ is the duration of maintenance in an hour. The annualized replacement cost can be given as:

$\xi_{a, R}=\xi_{R} \times F_{R} \times S_{F F}\left(i, N_{c o m}\right)-S \times S_{F F}\left(i, N_{c o m}\right)$

where, $S_{F F}$ is the sinking fund factor, $S$ is the salvage value of the component, $N_{c o m}$ is the actual lifetime of the component (in years). The $F_{R}$, considered in equation (17) as the component lifetime, may differ from the project lifetime.

$F_{R}= \begin{cases}\frac{C R F\left(i, N_{p r o j}\right)}{C R F\left(i, N_{R}\right)} & ; N_{\text {proj }}>0 \\ 0 & ; N_{\text {proj }}=0\end{cases}$

where, $N_{R}$, the replacement cost duration, can be expressed as (Suresh et al., 2020):

$N_{R}=N_{\text {com }} \times I N T\left(\frac{N_{\text {proj }}}{N_{\text {com }}}\right)$

where, INT stands for the integer value. The salvage value $S$ of the component can be expressed as:

$S=\xi_{R} \times \frac{N_{\text {rem }}}{N_{\text {com }}}$ 
$N_{\text {rem }}=N_{\text {com }}-\left(N_{\text {proj }}-N_{R}\right)$

where, $N_{r e m}$ is the number of years remaining to end the project. The sinking fund factor $\left(S_{F F}\right)$, included in the problem formulation to calculate the future value of the annual cash flow, is expressed as:

$S_{F F}=\frac{i}{(1+i)^{N}-1}$

where, $N$ is the year in the future. For calculating the economic viability of the system, the levelized cost of energy (LCOE) is calculated as follows:

$L C O E=\frac{C_{a t}}{E_{a, d}}$

where, $E_{a . d}$ is the annualized energy demand.

\subsection{Constraints}

The objective function is optimized based on the following constraints.

\subsubsection{Power Reliability Constraint}

The annual unmet load $\left(L_{\text {unmet }}\right)$ is considered as the power reliability constraint in this study. The power reliability constraint is the ratio of total capacity shortage $\left(L_{\text {shortage }}\right)$ to the annualized demand.

$L_{\text {unmet }}=\frac{L_{\text {shortage }}}{E_{a, d}}$

\subsubsection{Battery Storage System (BSS) Energy Constraints}

The BSS energy constraints, as the maximum $\left(E_{B S S, \max }\right)$ and minimum $\left(E_{B S S, \min }\right)$ capacity, are given as:

$E_{B S S, \min } \leq E_{B S S}(t) \leq E_{B S S, \max }$

The minimum and maximum capacity of the BSS is a function of its $\mathrm{SoC}$, as shown in equation (26) and (27):

$$
\begin{aligned}
& E_{B S S, \text { max }}=\frac{N_{b a t} V_{b a t} B_{a h}}{1000} \times S o C_{\max } \\
& E_{B S S, \text { min }}=\frac{N_{b a t} V_{b a t} B_{a h}}{1000} \times S o C_{\min }
\end{aligned}
$$

where, $N_{b a t}$ is the number of batteries in the bank, $V_{b a t}$ is the terminal voltage of BSS, and $B_{a h}$ is the BSS capacity in ampere-Hour.

\subsubsection{Upper and Lower Bound Constraints}

This constraint defines the maximum safe limit of RES penetration. The upper and lower bound constraints consist of the maximum and the minimum numbers of solar PV panels and the PEMFC arrays. This constraint mathematically can be expressed as:

$0 \leq N_{P V} \leq N_{P V}^{\max }$ 
where, $N_{P V}{ }^{\max }$, and $N_{F C}{ }^{\max }$ are the maximum number of solar PV modules and PEMFC module, respectively.

\section{Results and Discussion}

HOMER Pro software developed by NREL is used to conduct the simulation and economic analysis of the HPS. The system is designed in various combinations described as four combinations. The NPC, LCOE, pollutant emission, power generation, and unmet/ excess loads have been calculated for each combination. The HOMER Pro simulation figure for various combinations considered is shown in Figure 5. The cost of each component of the system has been adopted from (Akram et al., 2020; Murugaperumal \& Ajay D Vimal Raj, 2019; Oulis Rousis et al., 2018). The Homer load following algorithm is used in all the combinations for obtaining the optimized result. The technical and economic details of the various components used are tabulated in Table 1.

Table 1. Techno-economical details of the HPS components.

\begin{tabular}{|c|c|c|c|c|}
\hline \multirow[t]{2}{*}{ Component } & \multirow{2}{*}{$\begin{array}{c}\text { Maximum } \\
\text { capacity }\end{array}$} & \multicolumn{3}{|c|}{ Cost } \\
\hline & & Capital cost & Replacement cost & Operational and maintenance cost \\
\hline Diesel generator & $1400 \mathrm{~kW}$ & $1000 \mathrm{US} \$ / \mathrm{kW}$ & $1000 \mathrm{US} \$ / \mathrm{kW}$ & $5 \mathrm{US} \$ / \mathrm{kW} /$ Year \\
\hline Converter & $4500 \mathrm{~kW}$ & $250 \mathrm{US} \$ / \mathrm{kW}$ & $250 \mathrm{US} \$ / \mathrm{kW}$ & $10 \mathrm{US} \$ / \mathrm{kW} /$ Year \\
\hline Electrolyzer & $2000 \mathrm{~kW}$ & 1300 US $\$ / \mathrm{kW}$ & $1300 \mathrm{US} \$ / \mathrm{kW}$ & 5 US \$/kW/Year \\
\hline Hydrogen Tank & 10000 Liter & 500 US \$/Liter & 500 US \$/Liter & 5 US \$/Liter/Year \\
\hline Solar PV & $4500 \mathrm{~kW}$ & 1000 US $\$ / \mathrm{kW}$ & $1000 \mathrm{US} \$ / \mathrm{kW}$ & 10 US $\$ / \mathrm{kW} /$ Year \\
\hline Battery & $2500 \mathrm{~kW}$ & $250 \mathrm{US} \$ / \mathrm{kW}$ & 250 US $\$ / \mathrm{kW}$ & $10 \mathrm{US} \$ / \mathrm{kW} /$ Year \\
\hline PEMFC & $2000 \mathrm{~kW}$ & $1500 \mathrm{US} \$ / \mathrm{kW}$ & $1500 \mathrm{US} \$ / \mathrm{kW}$ & 5 US \$/kW/Year \\
\hline
\end{tabular}
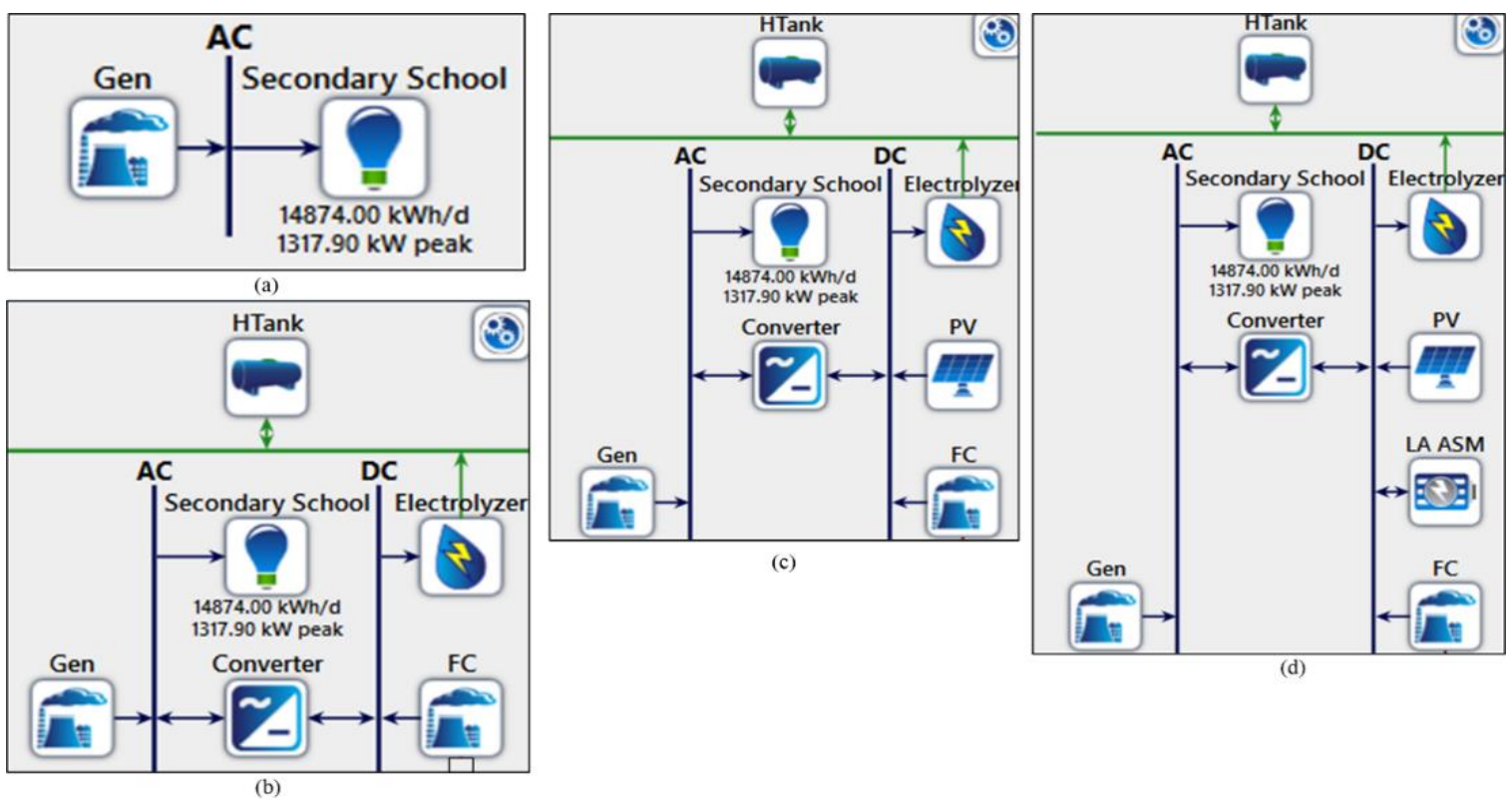

Figure 5. HOMER Pro simulation model. 


\subsection{Combination 1: Diesel-Generator (DG) only (Base case)}

In this combination, the entire load is assumed to be fed by the DG set. The load profile, DG power output, and the DG's excess electricity set for one year are plotted in Figure 6. The zoomed view of the power generation consumption for day 20 of May month is shown in Figure 7. The excess electricity is wasted in this combination since there is no other storage element present. The unmet load in this combination is zero; however, the excess electricity produced causes enormous loss. The emission of different pollutant gas in this combination is plotted in Figure. 8.

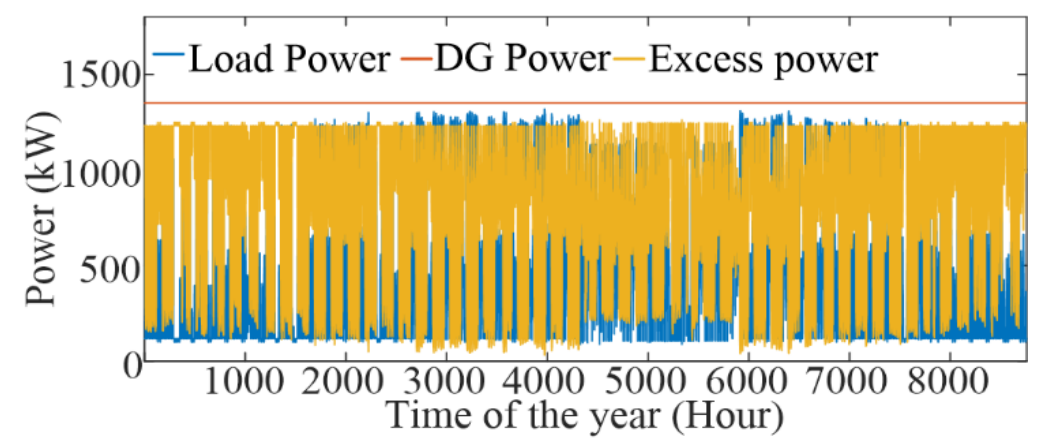

Figure 6. Power generation and consumption over the year: combination 1.

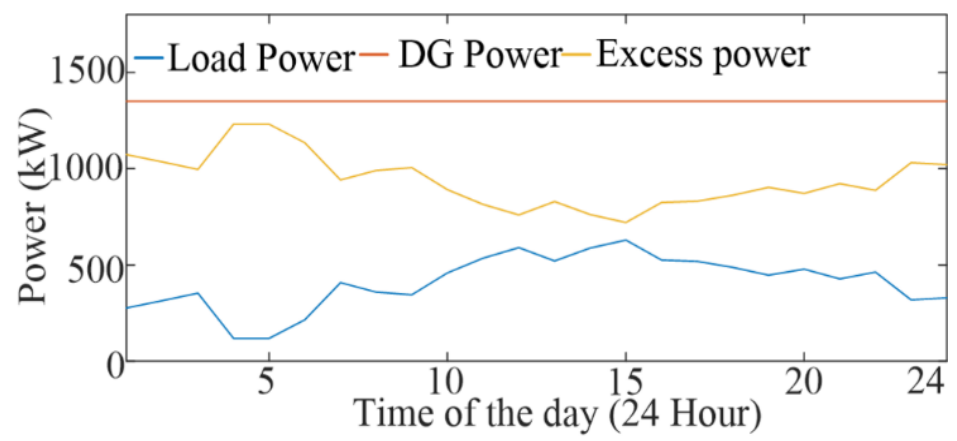

Figure 7. Power generation and consumption for one day: combination 1.

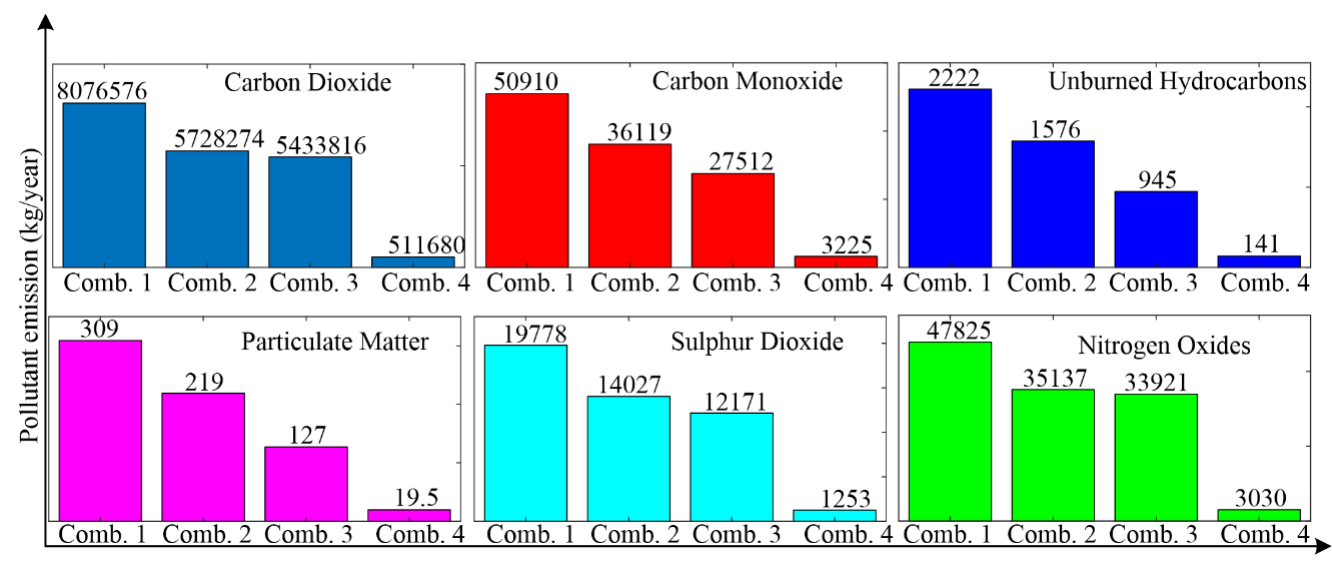

Figure 8. Comparison of pollutants emission: combination 1, 2, 3 \& 4 . 
The percentage pollutants emission of carbon dioxide $\left(\mathrm{CO}_{2}\right)$, carbon monoxide $(\mathrm{CO})$, unburned hydrocarbons (UHC), particulate matter (PM), sulfur dioxide $\left(\mathrm{SO}_{2}\right)$ and nitrogen oxide (NO) for all the combination in comparison with combination 1 are summarized in Table 2. Since combination 1 is considered the reference, the pollutant emission from combination 1 is $100 \%$.

Table 2. Percentage pollutant emissions for various combinations.

\begin{tabular}{|c|c|c|c|c|}
\hline Pollutant & Combination 1 & Combination 2 & Combination 3 & Combination 4 \\
\hline Carbon dioxide & 100 & 71 & 67 & 6 \\
\hline Carbon monoxide & 100 & 71 & 54 & 6 \\
\hline Unburned hydrocarbons & 100 & 71 & 43 & 6 \\
\hline Particulate matter & 100 & 71 & 42 & 6 \\
\hline Sulphur dioxide & 100 & 71 & 62 & 6 \\
\hline Nitrogen oxide & 100 & 74 & 21 & 6 \\
\hline
\end{tabular}

\subsection{Combination 2: DG-PEMFC-HES}

In combination 2, the PEMFC with HES is added to combination 1, and the performance has been analyzed. The hourly power generation from the sources and consumed by the load for a one-year duration is shown in Figure 9. The zoomed view of Figure 9 is depicted in Figure 10, for the day 20 of May month. Here, the excess power generated from the sources is diverted to the electrolyzer to produce Hydrogen. The amount of Hydrogen produced and stored is shown in Figure 11. The significant reduction in pollutant emissions in combination 2, compared to combination 1 , as shown in Figure 8, is due to the inclusion of eco-friendly PEMFC.

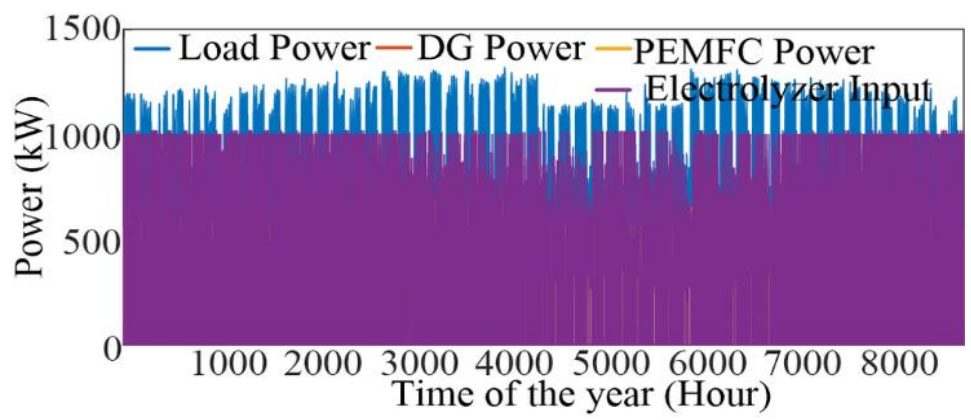

Figure 9. Power generation and consumption over the year: combination 2.

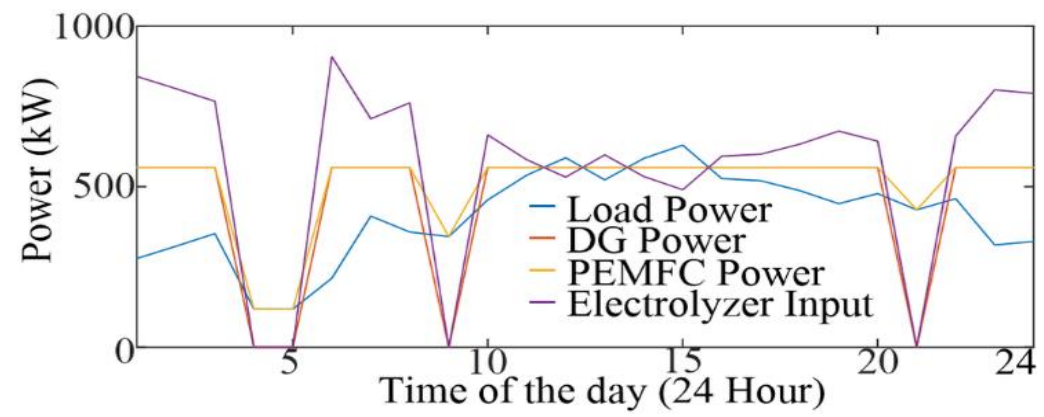

Figure 10. Power generation and consumption for one day: combination 2. 


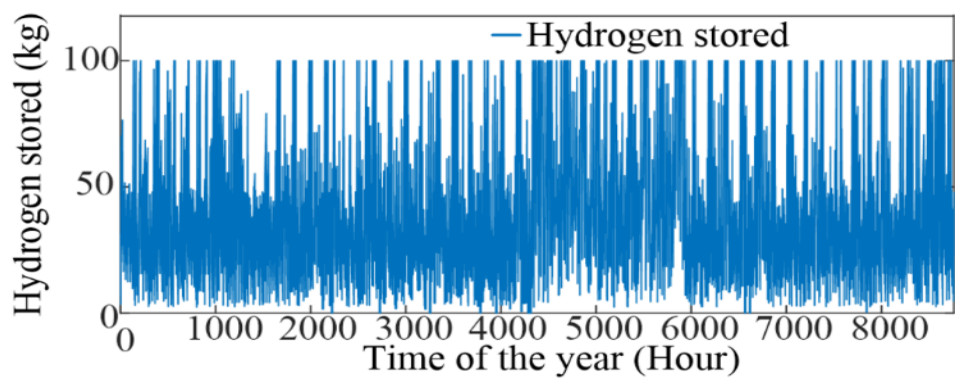

Figure 11. Hydrogen production over the year: combination 2.

\subsection{Combination 3: DG-Solar PV-PEMFC-HES}

In combination 3, the solar PV is added in combination 2. The power generation and consumption plot are shown in Figure 12. The plot depicts the power generation consumption curve for a oneyear duration on an hourly basis. The zoomed view by considering day 20 of May month is shown in Figure 13. It is noticeable from Figure 13 that the energy management is satisfied with zero energy loss or zero unmet loads. Also, the addition of solar PV further noticeably decreases the pollutant emissions, as shown in Figure 8.

Moreover, the excess power generated is stored as Hydrogen with the help of an electrolyzer. The Hydrogen stored over one year is shown in Figure 14. Here, it is lucidly observable that the hydrogen production in this combination is significantly declined than combination 2 . Therefore, solar PV reduces the power generation requirement from the DG and PEMFC, leading to lesser hydrogen production as fuel requirement of PEMFC.

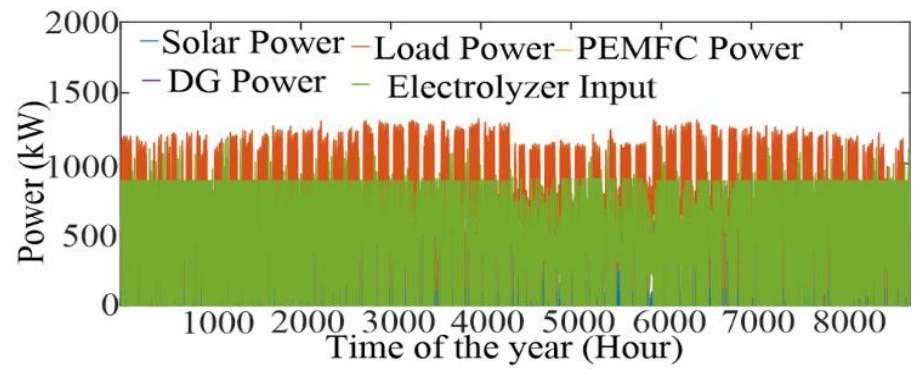

Figure 12. Power generation and consumption over the year: combination 3.

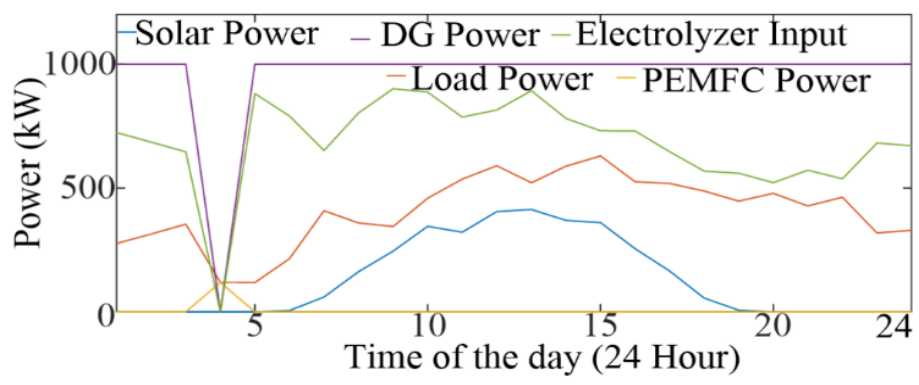

Figure 13. Power generation and consumption for one day: combination 3. 


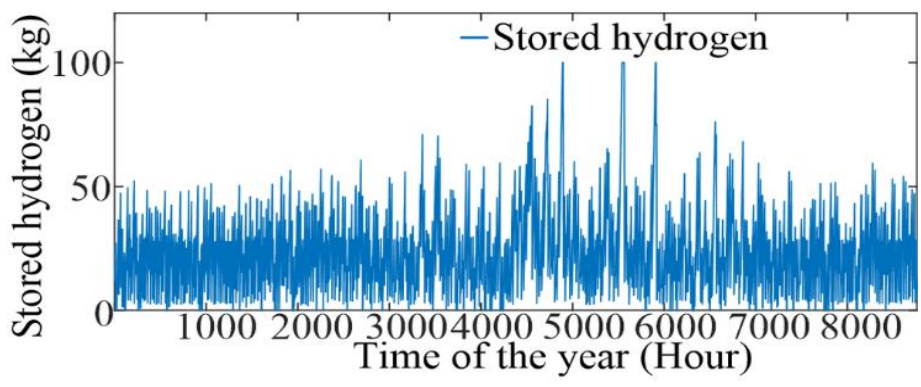

Figure 14. Hydrogen production over the year: combination 3.

\subsection{Combination 4: DG-Solar PV-PEMFC-HES-BSS}

In this combination, the BSS as an additional ESS is added to the system. The addition of BSS reduces costly PEMFC and electrolyzer, thus reducing overall operation and maintenance costs. The excess power generated in this combination is diverted to electrolyzer and BSS, both. But more preference for energy storage is given to the BSS due to economic operation. The power generation and consumption curve for one-year durations shown in Figure 15.

Similarly, in previous combinations, the zoomed view by selecting the day 20 of May month is plotted in Figure 16. Since the power generation for solar PV is increased in this combination due to the availability of multi-storage options, the pollutant emission is further reduced, as shown in Figure 8. The hydrogen production over one year period on an hourly basis is shown in Figure 17. In this combination also the energy managements satisfied with zero energy loss or unmet load. It can be observed from Figure 17 that the hydrogen production is further reduced in comparison with combination 3 due to the addition of BSS. Here, the excess power production is shared among the HSS and BSS, reducing hydrogen production.

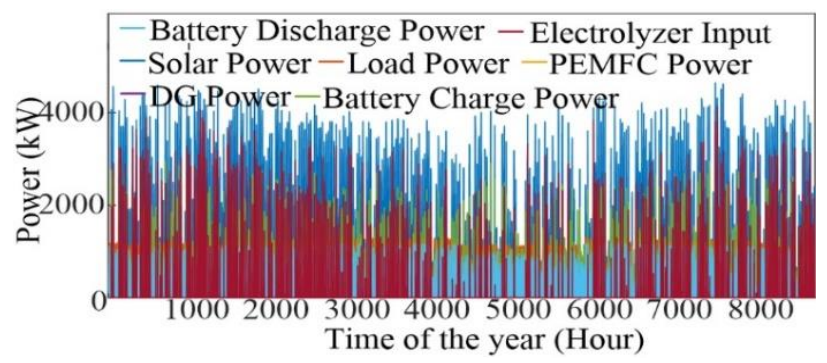

Figure 15. Power generation and consumption over the year: combination 4.

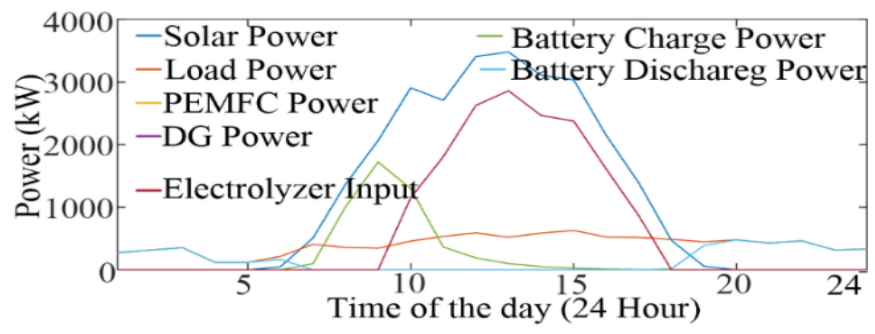

Figure 16. Power generation and consumption for one day: combination 4 . 


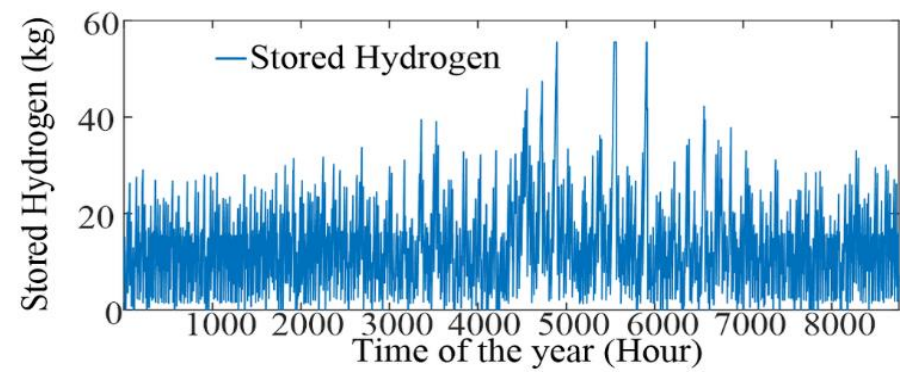

Figure 17. Hydrogen production over the year: combination 4.

\subsection{LCOE and NPC Comparison}

The levelized cost of energy (LCOE) and net present cost (NPC) are compared here to choose the best economic system from the combinations explained. As shown in Figure 18, the base combination system's LCOE and NPC model explained as combination 1 is high due to the high installation, operation, and maintenance cost of DG. On the other hand, the LCOE and NPC are progressively reduced in combination 2, combination 3 and is lowest in combination 4 . Therefore, the comparison (Table 3) shows that combination 4 with DG-Solar PV-PEMFC-HES-BSS is the best economic system.

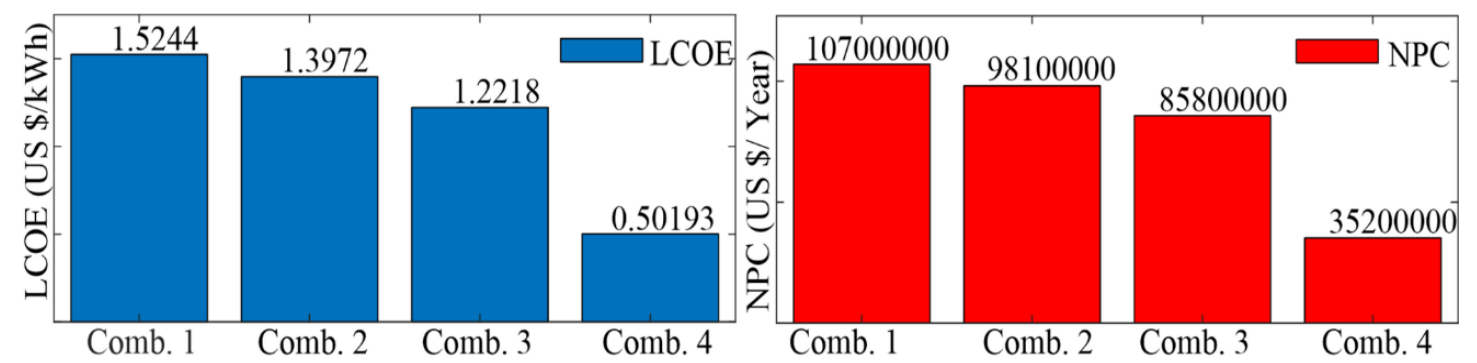

Figure 18. Comparison of LCOE and NPC: combination 1, 2, 3 \& 4.

Table 3. LCOE and NPC comparison of combination 1, 2, $3 \& 4$.

\begin{tabular}{|c|c|c|}
\hline Combination & LCOE (US \$/ kWh) & NPC (US \$) \\
\hline Combination 1 & 1.5244 & 107000000 \\
\hline Combination 2 & 1.3972 & 98100000 \\
\hline Combination 3 & 1.2218 & 85800000 \\
\hline Combination 4 & 0.50193 & 35200000 \\
\hline
\end{tabular}

\subsection{Sensitivity Analysis}

The sensitivity analysis was performed to investigate the system performance with change in some critical factors such as fuel price (US \$/liter) and interest rate. In this study, the fuel price increases from 1.1 US \$/liter to 1.3 US \$/liter with a step increase of 0.05 US \$/liter. The plot between LCOE and the diesel fuel price change for all four combinations is shown in Figure 19. It can be observed that the increase in diesel price causes an increase in the LCOE, establishing the diesel price as an 
influencing factor on the LCOE of the HPS. Over the last decades, the increase in diesel price highlights RES-based HPS in the power generation industry. Since the diesel price is increasing drastically, combination 4 with lesser LCOE and DG power production considered in this study is the better feasible system for long-term operation. By comparing all the combinations, it can be concluded that, in combination 1, the variation on LCOE is more due to the dependency of power production only on the DG. In combination 2 and combination 3, the variation in LCOE is further reduced as the power generation from DG is reduced due to PEMFC and solar PV. BSS increases the power production from solar PV, and the change in LCOE with diesel price variation is negligible in combination 4 due to the increased power share from the RESs.

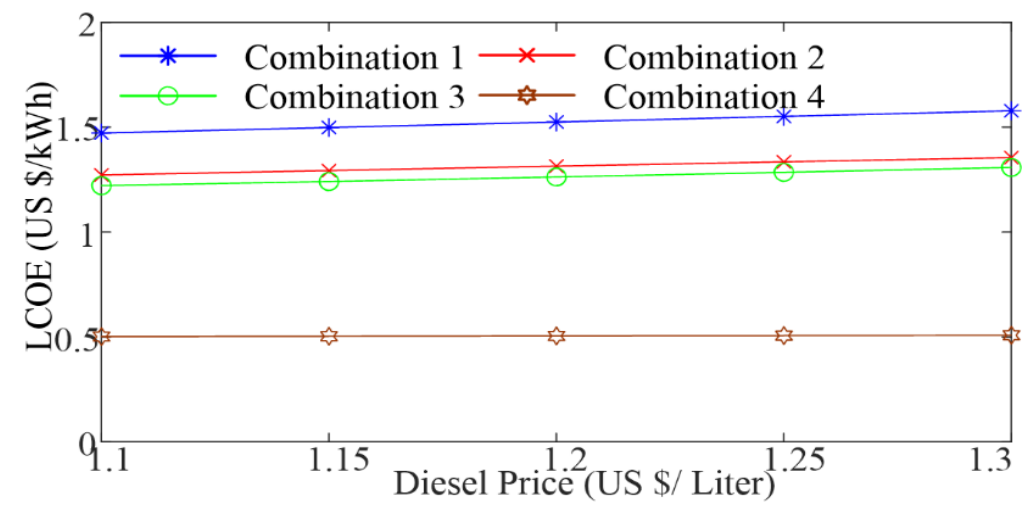

Figure 19. Variation of LCOE with variation in diesel price.

The rate of interest is considered as a sensitivity parameter in this study, also. A variation of 0 to $12 \%$ in the rate of interest with a step variation of $2 \%$ is considered in this analysis. The 'LCOE' vs. 'interest rate' plot, shown in Figure 20, depicts that the LCOE of the system is increasing with the rise in the interest rate. This indicates that the government subsidies and reduced interest rate on capital investment may promote RES-based HPS in rural electrification. There is a large variation in LCOE that can be observed in combination 4 due to the RESs. Since the capital cost is high in combination 4, and the rate of interest depends on the capital cost, the variation in LCOE is high in combination 4 compared to combinations 1,2 and 3 . Therefore, a base case rate of interest of $8 \%$ is considered in work.

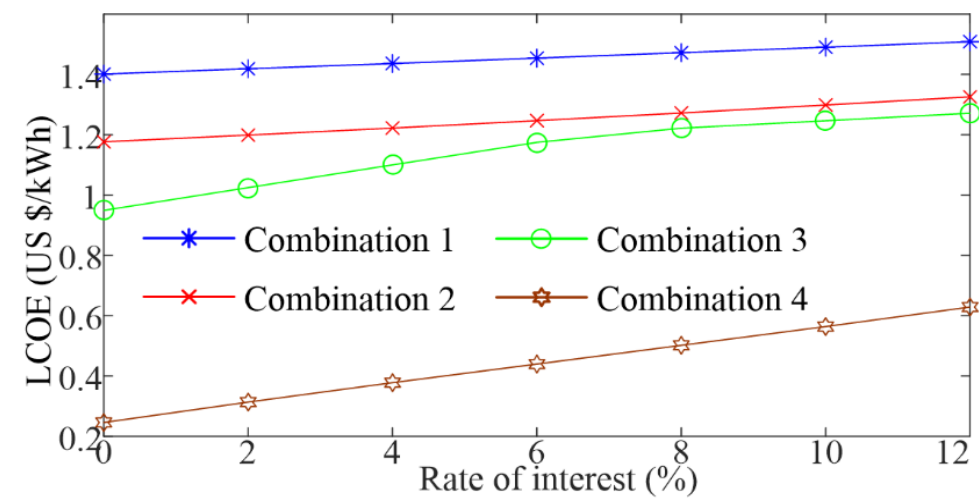

Figure 20. Variation of LCOE with variation in the rate of interest. 


\section{Conclusions}

This study investigates the various alternatives of HPS through Homer Pro to supply electrical power to the remotely located area where the extension of the utility grid is found economically expensive. Three different combinations of RESs, namely (i) proton exchange membrane fuel cell (PEMFC) and hydrogen energy storage (HES), (ii) PEMFC, HES, and Solar PV, and (iii) HES, Solar PV, PEMFC, HES, and battery storage system (BSS), respectively, are hybridized with DG to achieve the best alternative hybrid solution to supply electrical power in remotely located area efficiently and economically with least emission of pollutant. Through the comparative analysis, it has been revealed that the 'Combination 4' of the proposed study, i.e., hybridization of DG with HES, Solar PV, PEMFC, HES, and battery storage system (BSS), provides the best alternative solution of hybridization with $6 \%$ pollutant emission (i.e., reduction of $94 \%$ in pollution). Further, the least utilization DG for the 'Combination 4' may also be helpful to overcome the problems of the global warming crisis and depletion of conventional fuels. In addition, the effectiveness of the proposed hybridization, i.e., Combination 1 to Combination 4, has also been tested to find the most economical HPS. Economic assessment parameters, namely, NPC and LCOE, have been evaluated and compared for these combinations. The comparative study shows that 'Combination 4' has not only the least pollutant emission characteristics but also supplies energy economically. It is found that there is a $67 \%$ of reduction in LCOE and NPC for 'Combination 4' concerning 'Combination 1'. Therefore, this work suggests 'Combination 4' is the most suitable alternative solution of HPS to achieve electric power efficiently, eco-friendly, and economically. In future work, more parameters such as load demand, generation forecasting can be considered for sensitivity analysis. Moreover, the projected work can be practically implemented in areas where utility grid extension is unavailable. Other types of ESS and RESs can be considered in the future expansion of the work.

\section{Conflict of Interest}

We confirm that there is no conflict of interest to declare for publication of this paper.

\section{Acknowledgments}

We would like to express our sincere thanks to the Board of Research in Nuclear Sciences (BRNS), Department of Atomic Energy, Govt. of India, for the grant no: [34/14/53/2014-BRNS].

\section{References}

Ahmad, J., Imran, M., Khalid, A., Iqbal, W., Ashraf, S.R., Adnan, M., Ali, S.F., \& Khokhar, K.S. (2018). Techno economic analysis of a wind-photovoltaic-biomass hybrid renewable energy system for rural electrification: a case study of Kallar Kahar. Energy, 148, 208-234. https://doi.org/10.1016/j.energy.2018.01.133.

Akram, F., Asghar, F., Majeed, M.A., Amjad, W., Manzoor, M.O., \& Munir, A. (2020). Techno-economic optimization analysis of stand-alone renewable energy system for remote areas. Sustainable Energy Technologies and Assessments, 38, 100673. https://doi.org/10.1016/j.seta.2020.100673.

Arabul, F.K., Arabul, A.Y., Kumru, C.F., \& Boynuegri, A.R. (2017). Providing energy management of a fuel cell-battery-wind turbine-solar panel hybrid off grid smart home system. International Journal of Hydrogen Energy, 42(43), 26906-26913. https://doi.org/10.1016/j.ijhydene.2017.02.204.

Aziz, A.S., Tajuddin, M.F.N., Adzman, M.R., Azmi, A., \& Ramli, M.A.M. (2019). Optimization and sensitivity analysis of standalone hybrid energy systems for rural electrification: a case study of Iraq. Renewable Energy, 138, 775-792. https://doi.org/10.1016/j.renene.2019.02.004. 
Benlahbib, B., Bouarroudj, N., Mekhilef, S., Abdeldjalil, D., Abdelkrim, T., Bouchafaa, F., \& lakhdari, A. (2020). Experimental investigation of power management and control of a PV/wind/fuel cell/battery hybrid energy system microgrid. International Journal of Hydrogen Energy, 45(53), 29110-29122. https://doi.org/10.1016/j.ijhydene.2020.07.251.

Dali, M., Belhadj, J., \& Roboam, X. (2010). Hybrid solar-wind system with battery storage operating in gridconnected and standalone mode: control and energy management - experimental investigation. Energy, 35(6), 2587-2595. https://doi.org/10.1016/j.energy.2010.03.005.

Dalton, G.J., Lockington, D.A., \& Baldock, T.E. (2009). Feasibility analysis of renewable energy supply options for a grid-connected large hotel. Renewable Energy, 34(4), 955-964. https://doi.org/10.1016/j.renene.2008.08.012.

Das, B.K., Hoque, N., Mandal, S., Pal, T.K., \& Raihan, M.A. (2017). A techno-economic feasibility of a stand-alone hybrid power generation for remote area application in Bangladesh. Energy, 134, 775-788. https://doi.org/10.1016/j.energy.2017.06.024.

Das, V., Singh, A.K., Karuppanan, P., Kumar, P., Singh, S.N., \& Agelidis, V.G. (2020). Energy management and economic analysis of multiple energy storage systems in solar PV/PEMFC hybrid power systems. Energy Conversion and Economics, 1(2), 124-140. https://doi.org/10.1049/enc2.12011.

Dhundhara, S., Verma, Y.P., \& Williams, A. (2018). Techno-economic analysis of the lithium-ion and leadacid battery in microgrid systems. Energy Conversion and Management, 177, 122-142. https://doi.org/10.1016/j.enconman.2018.09.030.

Esfahani, I.J., \& Yoo, C. (2016). An optimization algorithm-based pinch analysis and GA for an off-grid batteryless photovoltaic-powered reverse osmosis desalination system. Renewable Energy, 91, 233-248. https://doi.org/10.1016/j.renene.2016.01.049.

Jannati, M., Foroutan, E., Mousavi, S.M.S., \& Grijalva, S. (2020). An intelligent energy management system to use parking lots as energy storage systems in smoothing short-term power fluctuations of renewable resources. Journal of Energy Storage, 32, 101905. https://doi.org/10.1016/j.est.2020.101905.

Kaluthanthrige, R., \& Rajapakse, A.D. (2021). Demand response integrated day-ahead energy management strategy for remote off-grid hybrid renewable energy systems. International Journal of Electrical Power \& Energy Systems, 129, 106731. https://doi.org/10.1016/j.ijepes.2020.106731.

Kannayeram, G., Prakash, N.B., \& Muniraj, R. (2020). Intelligent hybrid controller for power flow management of PV/battery/FC/SC system in smart grid applications. International Journal of Hydrogen Energy, 45(41), 21779-21795. https://doi.org/10.1016/j.ijhydene.2020.05.149.

Khalil, L., Liaquat Bhatti, K., Awan, M.A.I., Riaz, M., Khalil, K., \& Alwaz, N. (2020). Optimization and designing of hybrid power system using HOMER pro. Materials Today: Proceedings. Published. https://doi.org/10.1016/j.matpr.2020.06.054.

Krishan, O., \& Suhag, S. (2019). Techno-economic analysis of a hybrid renewable energy system for an energy poor rural community. Journal of Energy Storage, 23, 305-319. https://doi.org/10.1016/j.est.2019.04.002.

Kumar, P., Pukale, R., Kumabhar, N., \& Patil, U. (2016). Optimal design configuration using HOMER. Procedia Technology, 24, 499-504. https://doi.org/10.1016/j.protcy.2016.05.085.

Lande-Sudall, D., Stallard, T., \& Stansby, P. (2018). Co-located offshore wind and tidal stream turbines: assessment of energy yield and loading. Renewable Energy, 118, 627-643. https://doi.org/10.1016/j.renene.2017.10.063.

Lü, X., Qu, Y., Wang, Y., Qin, C., \& Liu, G. (2018). A comprehensive review on hybrid power system for PEMFC-HEV: issues and strategies. Energy Conversion and Management, 171, 1273-1291. https://doi.org/10.1016/j.enconman.2018.06.065. 
Mazzeo, D., Matera, N., De Luca, P., Baglivo, C., Congedo, P.M., \& Oliveti, G. (2021). A literature review and statistical analysis of photovoltaic-wind hybrid renewable system research by considering the most relevant 550 articles: an upgradable matrix literature database. Journal of Cleaner Production, 295, 126070. https://doi.org/10.1016/j.jclepro.2021.126070.

Muh, E., \& Tabet, F. (2019). Comparative analysis of hybrid renewable energy systems for off-grid applications in southern Cameroons. Renewable Energy, 135, 41-54. https://doi.org/10.1016/j.renene.2018.11.105.

Murugaperumal, K., \& Raj, P.A.D.V. (2019). Feasibility design and techno-economic analysis of hybrid renewable energy system for rural electrification. Solar Energy, 188, 1068-1083. https://doi.org/10.1016/j.solener.2019.07.008.

Oulis Rousis, A., Tzelepis, D., Konstantelos, I., Booth, C., \& Strbac, G. (2018). Design of a hybrid AC/DC microgrid using HOMER pro: case study on an islanded residential application. Inventions, 3(3), 55. https://doi.org/10.3390/inventions3030055.

Parida, A., Choudhury, S., \& Chatterjee, D. (2018). Microgrid based hybrid energy co-operative for gridisolated remote rural village power supply for east coast zone of India. IEEE Transactions on Sustainable Energy, 9(3), 1375-1383. https://doi.org/10.1109/tste.2017.2782007.

Rajbongshi, R., Borgohain, D., \& Mahapatra, S. (2017). Optimization of PV-biomass-diesel and grid base hybrid energy systems for rural electrification by using HOMER. Energy, 126, 461-474. https://doi.org/10.1016/j.energy.2017.03.056.

Restrepo, M., Cañizares, C.A., Simpson-Porco, J.W., Su, P., \& Taruc, J. (2021). Optimization- and rulebased energy management systems at the Canadian renewable energy laboratory microgrid facility. Applied Energy, 290, 116760. https://doi.org/10.1016/j.apenergy.2021.116760.

Salameh, T., Abdelkareem, M.A., Olabi, A.G., Sayed, E.T., Al-Chaderchi, M., \& Rezk, H. (2021). Integrated standalone hybrid solar PV, fuel cell and diesel generator power system for battery or supercapacitor storage systems in khorfakkan, United Arab Emirates. International Journal of Hydrogen Energy, 46(8), 6014-6027. https://doi.org/10.1016/j.ijhydene.2020.08.153.

Shabani, M., Dahlquist, E., Wallin, F., \& Yan, J. (2020). Techno-economic comparison of optimal design of renewable-battery storage and renewable micro pumped hydro storage power supply systems: a case study in Sweden. Applied Energy, 279, 115830. https://doi.org/10.1016/j.apenergy.2020.115830.

Sultan, H.M., Menesy, A.S., Kamel, S., Korashy, A., Almohaimeed, S.A., \& Abdel-Akher, M. (2021). An improved artificial ecosystem optimization algorithm for optimal configuration of a hybrid PV/WT/FC energy system. Alexandria Engineering Journal, 60(1), 1001-1025. https://doi.org/10.1016/j.aej.2020.10.027.

Suman, G.K., Guerrero, J.M., \& Roy, O.P. (2021). Optimisation of solar/wind/bio-generator/diesel/battery based microgrids for rural areas: A PSO-GWO approach. Sustainable Cities and Society, 67, 102723. https://doi.org/10.1016/j.scs.2021.102723.

Suresh, V., Muralidhar, M., \& Kiranmayi, R. (2020). Modelling and optimization of an off-grid hybrid renewable energy system for electrification in a rural areas. Energy Reports, 6, 594-604. https://doi.org/10.1016/j.egyr.2020.01.013.

Talaat, M., Elgarhy, A., Elkholy, M.H., \& Farahat, M.A. (2021). Integration of fuel cells into an off-grid hybrid system using wave and solar energy. International Journal of Electrical Power \& Energy Systems, 130, 106939. https://doi.org/10.1016/j.ijepes.2021.106939.

Wang, J., Zhou, Y., Zhang, X., Ma, Z., Gao, Y., Liu, B., \& Qin, Y. (2021). Robust multi-objective optimization with life cycle assessment of hybrid solar combined cooling, heating and power system. Energy Conversion and Management, 232, 113868. https://doi.org/10.1016/j.enconman.2021.113868. 
Wen, X. (2020). Modeling and performance evaluation of wind turbine based on ant colony optimizationextreme learning machine. Applied Soft Computing, 94, 106476. https://doi.org/10.1016/j.asoc.2020.106476.

Yuan, G., \& Yang, W. (2019). Study on optimization of economic dispatching of electric power system based on hybrid intelligent algorithms (PSO and AFSA). Energy, 183, 926-935. https://doi.org/10.1016/j.energy.2019.07.008.

Zhang, G., Hu, W., Cao, D., Liu, W., Huang, R., Huang, Q., Chen, Z., \& Blaabjerg, F. (2021). Data-driven optimal energy management for a wind-solar-diesel-battery-reverse osmosis hybrid energy system using a deep reinforcement learning approach. Energy Conversion and Management, 227, 113608. https://doi.org/10.1016/j.enconman.2020.113608. 